\title{
The obesity-related polymorphism PCSK1 rs6235 is associated with essential hypertension in the Han Chinese population
}

\begin{abstract}
Xiao-mu Li ${ }^{1}$, Yan Ling ${ }^{1}$, Da-ru Lu ${ }^{2}$, Zhi-qiang $\mathrm{Lu}^{1}$, Ying Liu ${ }^{1}$, Hong-yan $\mathrm{Chen}^{2}$ and Xin Gao ${ }^{1}$
Proprotein convertase subtilisin/kexin-type 1 (PCSK1) is a prohormone convertase that has an important role in prohormone maturation including the process of prorenin to renin. We studied the association of the PCSK 1 single-nucleotide polymorphism (SNP) rs6235 (encoding an S690T substitution) with essential hypertension (EH), obesity and related traits in the Han Chinese population. The rs6235 SNP in the PCSK1 gene was investigated using a case-control study design, with 1034 hypertension cases and 1112 normotensive controls. In this study, the rs6235 SNP was significantly associated with hypertension $(\mathrm{OR}=1.26,95 \% \mathrm{Cl}(1.10-1.46), P=0.001)$; the odds ratios of GC vs GG and CC vs GG were $1.30(95 \% \mathrm{Cl}(1.06-1.58)$, $\boldsymbol{P}=0.010)$ and $1.55(95 \% \mathrm{Cl}(1.12-2.13), \boldsymbol{P}=0.007)$, respectively. In the controls, the C-allele was associated with increased systolic $(P=0.010)$ and diastolic $(P=0.010)$ blood pressure levels. In all of the EH patients and EH patients without a history of renin-angiotensin-aldosterone (RAA) system-related antagonists, the $C$-allele was associated with increased plasma renin activity $(P=0.00004$ and 0.002 , respectively) and aldosterone levels $(P=0.018$ and 0.005 , respectively). The $C$-allele was also associated with increased body mass index $(\mathrm{BMI})(P=0.010)$ in the normotensive controls. In conclusion, the PCSK1 SNP rs6235 was associated with EH and blood pressure in the Han Chinese population, and this association may be mediated by the SNP's effect on RAA levels. rs6235 was also associated with BMI in this population.

Hypertension Research (2012) 35, 994-999; doi:10.1038/hr.2012.79; published online 17 May 2012
\end{abstract}

Keywords: obesity; PCSK1; renin

\section{INTRODUCTION}

Convertase subtilisin/kexin-type 1 (PCSK1, PC1/3) is a member of the proprotein covertase family. PCSK1 has a primary role in the proteolytic conversion of inactive prohormones to mature bioactive hormones, including the cleavage of the large inactive precursor proteins, proopiomelanocortin, proinsulin, proglucagon, proislet amyloid polypeptide and prorenin at specific paired basic residues. ${ }^{1,2}$ These products are involved in a wide range of processes, including energy balance, glucose metabolism and blood pressure (BP) regulation.

PCSK1, which is encoded by the PCSK1 gene, is selectively expressed in neuronal and endocrine tissues and has critical roles in various processes. ${ }^{3}$ The PCSK1 gene maps to chromosome 5 q15. In humans, loss-of-function mutations in PCSK1 cause monogenic obesity, impaired glucose tolerance and other related disorders. ${ }^{4-6}$ In both genome-wide linkage studies ${ }^{7-10}$ and candidate gene strategy studies, ${ }^{11}$ single-nucleotide polymorphisms (SNPs) in the PCSK1 gene were associated with obesity. Most of these studies focused on the SNPs rs6232 and rs6235. ${ }^{11-13}$ It was also reported that these two PCSK1 SNPs were associated with proinsulin conversion. ${ }^{12}$ The PCSK1 SNP rs6234, which is in strong linkage disequilibrium with rs6235 and encodes the Q655E-S690T pair of residues in the C terminus of the PCSK1 protein, was also associated with body mass index (BMI) and being overweight in men in a population-based sample of Han Chinese subjects. ${ }^{14}$

PCSK1 is also involved in the proteolytic processing of prorenin to renin, this phenomenon has been demonstrated in cells containing secretory granules, such as the somatomammotroph cell line GH4 and Chinese hamster ovary' cells. ${ }^{15}$ Renin is important in the reninangiotensin-aldosterone system (RAAS) and may regulate vasoconstriction and BP via angiotensin-dependent and -independent mechanisms, ${ }^{16-18}$ thereby facilitating hypertension, cardiac remodeling and microvascular damage.

Both obesity and hypertension are the common risk factors for cardiovascular diseases. ${ }^{19}$ With regard to the association of PCSK1 with obesity and renin maturation, the associations of PCSK1 polymorphisms with essential hypertension $(\mathrm{EH})$ and RAAS need to be further investigated. Because the minor allele frequency of the rs6232 SNP was not sufficiently high to allow a meaningful analysis in

${ }^{1}$ Department of Endocrinology and Metabolism, Zhongshan Hospital, Fudan University, Shanghai, China and ${ }^{2}$ The State Key Laboratory of Genetic Engineering and the Key Laboratory of Contemporary Anthropology, School of Life Sciences, Fudan University, Shanghai, China

Correspondence: Dr X Gao, Department of Endocrinology and Metabolism, Zhongshan Hospital, Fudan University, 180 Fenglin Road, Shanghai 200032 , China. E-mail: zhongshan_endo@126.com or gao.xin@zs-hospital.sh.cn

Received 7 December 2011; revised 1 April 2012; accepted 2 April 2012; published online 17 May 2012 
the Chinese population, we investigated the rs6235 SNP in the present study. Thus, the aim of this study was to evaluate the association of the previously reported obesity-related polymorphism rs6235 in the PCSK1 gene with hypertension and related traits in the Han Chinese population.

\section{METHODS}

\section{Study population}

All of the participants were from Han Chinese ancestry and resided in the metropolitan Shanghai region China. In total, $1059 \mathrm{EH}$ patients were recruited from the Hypertension clinic of Zhongshan Hospital, Fudan University, Shanghai, China. All of the EH cases met the 1999 WHO/ISH criteria. ${ }^{20}$ A total of 1120 unrelated control participants were selected among individuals who were undergoing a health examination at Zhongshan Hospital. These individuals had normal BP levels (defined as a systolic BP (SBP) $<130 \mathrm{~mm} \mathrm{Hg}$ and a diastolic BP (DBP) $<80 \mathrm{~mm} \mathrm{Hg}$ ). None of the controls had a history of taking antihypertensive medication. The control participants also had normal fasting blood glucose levels $\left(<5.6 \mathrm{mmoll}^{-1}\right)$ and no history of taking a hypoglycemic agent. All of the control subjects were over 40 years of age. Obesity was defined as a BMI $\geqslant 28 \mathrm{~kg} \mathrm{~m}^{-2}$ according to the criteria for Chinese individuals. ${ }^{21}$

Written, informed consent was obtained from all of the participants, and the study was approved by the ethics committee of Zhongshan Hospital, Fudan University, China.

\section{Clinical measurements}

The phenotypes of the patients and controls were extensively characterized for related anthropometric traits. The anthropometric measures were performed and evaluated by trained medical personnel. Weight $(\mathrm{kg})$ and height $(\mathrm{m})$ were measured when the subjects were wearing only undergarments and no shoes. These measurements were then used to calculate BMI in weight divided by height. ${ }^{2}$ Waist circumference was measured with flexible tape at the smallest horizontal circumference between the costal margin and the iliac crest. SBP and DBP were measured by a nurse using a mercury sphygmomanometer that was adapted for arm size following 5-min of rest with the participant lying in the supine position. Two measures of BP were taken at 5-min intervals, and the mean values were used for the analysis. All antihypertensive medications and other related medications were recorded.

Blood samples were obtained after an overnight fast for measuring fasting glucose levels and lipid profiles, including total cholesterol, triglyceride, highdensity lipoprotein cholesterol (HDL-C) in all participants, serum sodium and potassium levels in $\mathrm{EH}$ patients with standardized equipment, low-density lipoprotein was calculated by the Friedewald equation. Additionally, in the EH patients, plasma renin activity (PRA), angiotensin II (ANG II) and aldosterone (ALD) levels were measured by radioimmunoassay (North institute of biological technology, Beijing, China). On the morning of admission, the blood samples were obtained and measured after the participant maintained an upright posture for $90 \mathrm{~min}$ and sitting for $10 \mathrm{~min}$ at 0800 hours to avoid the confounding effects of posture or diurnal variation. All of the immunoassays were performed in duplicate. In the present study, circulating renin levels were measured using the PRA assay, which is one of the most commonly used methods for measuring plasma renin. ${ }^{22}$ In the absence of renin inhibitors or other RAAS-related antagonists, activity assays provide information regarding the quantity of enzymatically active renin in the plasma. ${ }^{22}$

\section{Genotyping}

We selected the SNP rs6235 in the PCSK1 gene for analysis in the present study. Genotyping was performed by matrix-assisted laser desorption/ionization time-of-flight mass spectroscopy using a MassARRAY platform (MassARRAY Compact Analyzer, Sequenom, San Diego, CA, USA). The call rate was $98.9 \%$, and the concordance rate of the SNPs based on 120 duplicates was $100 \%$.

\section{Statistical analysis}

Normally continuous variables are expressed as the mean \pm s.d.; the nonnormally distributed variables are expressed as the median and inter quartile range. Comparisons between the groups were performed with Student's $t$-test and $\chi^{2}$-test for normally distributed continuous and categorical variables, respectively. Deviation from Hardy-Weinberg equilibrium was assessed using a $\chi^{2}$-test. We tested the association of the polymorphism with the diseases using logistic regression. Multivariate linear regression was used to test for the association of the polymorphism with quantitative traits. Non-normally distributed values were $\log$ transformed before analysis. All of the models were adjusted for age, sex and BMI unless otherwise noted. The analyses were performed using SPSS software for Windows, version 13.0 (SPSS, Chicago, IL, USA). Permutations (10000 times) were performed for each trait to assess the empirical $P$-values using PLINK ${ }^{23}$ to adjust the multiple comparisons. The statistical power of our sample size was $98 \%$ for the case-control study of $\mathrm{EH}$ vs the controls (calculated by $\mathrm{G}^{*}$ power, version 3.1, Heinrich Heine University, Düsseldorf Germany).

\section{RESULTS}

\section{Population characteristics}

The characteristics of the participants in this study are presented in Table 1. Of the 2146 participants, 1034 were EH cases and 1112 were normotensive controls. The EH patients were older and had higher BMI, waist circumference, SBP, DBP, fasting plasma glucose, total cholesterol, triglyceride and low-density lipoprotein cholesterol levels, and lower high-density lipoprotein cholesterol levels, than the controls. The distribution of gender and the smoking status were similar between the cases and controls (Table 1 and Supplementary Table 1).

The SNP rs6235 was selected and genotyped in the present study. The rs6235 SNP satisfied the Hardy-Weinberg equilibrium in the total population $\left(\chi^{2}=0.003, P=0.95\right)$ and in the normotensive controls $\left(\chi^{2}=0.447, P=0.50\right)$. Genotyping was successfully carried out for 1023 of $1034(98.9 \%)$ cases and 1100 out of 1112 (98.9\%) controls.

\section{Associations of rs6235 with EH and BP}

After adjusting for age, gender, BMI and smoking status, we observed a significantly higher frequency of the PCSK1 rs6235 C-allele in the hypertensive patients than in the normotensive controls $(\mathrm{OR}=1.27$, 95\% CI (1.10-1.29), $P=0.001)$. The PCSK1 rs6235 SNP was significantly associated with hypertension in an additive genetic model (CC vs CG vs GG, OR=1.26, 95\% CI (1.10-1.46), $P=0.001)$. The odds ratios of CG vs GG and CC vs GG were 1.30 (95\% CI (1.06-1.58), $P=0.010)$ and 1.55 (95\% CI (1.12-2.13), $P=0.007$ ), respectively (Table 2 ). As fasting glucose levels of the hypertensive patients were higher than the control subjects, we also did the multiple logistic regression analysis after adjusting for age, gender, BMI, smoking status and fasting glucose levels, rs6235 was still significantly associated with hypertension in our population (in an additive genetic model CC vs CG vs GG, OR $=1.29,95 \% \mathrm{CI}$ (1.10-1.51), $P=0.002)$. (Supplementary Table 2).

In the controls, the risk $\mathrm{C}$-allele was nominally associated with increased SBP $(P=0.010)$ and DBP $(P=0.010)$ levels after adjusting for age, gender and BMI (Table 3). After correction of multiple comparisons using 10000 permutations, the associations of rs6235 with SBP and DBP remained significant (with empirical $P$-values of 0.009 and 0.003 , respectively) in normotensive controls.

\section{Associations of rs6235 with RAAS in the EH patients}

After adjusting for gender, age, BMI and antihypertension medication, including RAAS-related antagonists (for example, angiotensinconverting enzyme inhibitors, angiotensin II receptor blockers and 
Table 1 Population characteristics of cases of essential hypertension and normotension control participants

\begin{tabular}{|c|c|c|c|c|c|c|}
\hline & \multirow[b]{2}{*}{ Hypertension $(\mathrm{n}=1034)$} & \multirow[b]{2}{*}{ Normotension $(\mathrm{n}=1112)$} & \multirow[b]{2}{*}{ P-value* } & \multicolumn{2}{|c|}{ Obesity in normotension } & \multirow[b]{2}{*}{ P-value** } \\
\hline & & & & Obese $(n=50)$ & Non-obese $(\mathrm{n}=1062)$ & \\
\hline Age (years) & $61.4 \pm 10.3$ & $55.8 \pm 10.9$ & $<0.001$ & $56.0 \pm 10.2$ & $56.1 \pm 10.7$ & 0.856 \\
\hline Men (\%) & 43.8 & 41.5 & 0.273 & 53.1 & 40.8 & 0.089 \\
\hline Body mass index $\left(\mathrm{kgm}^{-2}\right)$ & $25.3 \pm 3.4$ & $23.2 \pm 2.9$ & $<0.001$ & $29.3 \pm 1.0$ & $22.9 \pm 2.5$ & $<0.001$ \\
\hline Waist circumference $(\mathrm{cm})$ & $87.5 \pm 10.7$ & $79.3 \pm 8.5$ & $<0.001$ & $82.0 \pm 7.3$ & $78.7 \pm 8.1$ & $<0.001$ \\
\hline Fasting glucose (mmoll-1) & $5.7 \pm 1.5$ & $4.8 \pm 0.4$ & $<0.001$ & $4.9 \pm 0.4$ & $4.8 \pm 0.4$ & 0.081 \\
\hline Systolic blood pressure (mm Hg) & $142.0 \pm 17.1$ & $116.6 \pm 14.1$ & $<0.001$ & $123.86 \pm 13.1$ & $116.2 \pm 14.1$ & $<0.001$ \\
\hline Diastolic blood pressure $(\mathrm{mm} \mathrm{Hg})$ & $83.9 \pm 10.2$ & $76.5 \pm 8.9$ & $<0.001$ & $82.1 \pm 7.8$ & $76.3 \pm 8.8$ & $<0.001$ \\
\hline Smoking (present) (\%) & 22.0 & 20.0 & 0.253 & 24.0 & 19.8 & 0.514 \\
\hline Smoking (before) (\%) & 10.0 & 8.0 & 0.110 & 10.0 & 7.9 & 0.594 \\
\hline
\end{tabular}

Continuous data are expressed as means \pm s.d.

* $P$-value for comparison between hypertension and normotension groups, adjusted for age and percentage of men (except the comparison for age and percentage of men).

**P-value for comparison between obese and non-obese groups, adjusted for age and percentage of men (except the comparison for age and percentage of men).

Table 2 The associations of rs6235 and essential hypertension

\begin{tabular}{|c|c|c|c|c|c|c|c|c|c|c|c|}
\hline \multicolumn{3}{|c|}{ Allele frequency } & \multirow[b]{2}{*}{ OR $(95 \% \mathrm{Cl})^{*}$} & \multirow[b]{2}{*}{$P^{*}$} & \multicolumn{3}{|c|}{ Genotype distribution } & \multirow[b]{2}{*}{ OR $(95 \% C I)^{a}$} & \multirow[b]{2}{*}{$\mathrm{P}^{\mathrm{a}}$} & \multirow[b]{2}{*}{ OR $(95 \% \mathrm{Cl})^{* *}$} & \multirow[b]{2}{*}{$\mathrm{P}$ add** } \\
\hline & Controls (\%) & Cases (\%) & & & Genotype & Controls n (\%) & Cases n (\%) & & & & \\
\hline G & 69.9 & 63.9 & & & GG & $538(48.9)$ & 409 (40.0) & 1.00 (ref.) & & & \\
\hline \multirow[t]{2}{*}{ C } & 30.1 & 36.1 & $1.27(1.10-1.29)$ & 0.001 & CG & $462(42.0)$ & 490 (47.9) & $1.30(1.06-1.1 .58)$ & 0.010 & $1.26(1.10-1.46)$ & 0.001 \\
\hline & & & & & $\mathrm{CC}$ & $100(9.1)$ & $124(12.1)$ & $1.55(1.12-2.13)$ & 0.007 & & \\
\hline
\end{tabular}

Abbreviations: $\mathrm{Cl}$, confidence interval; OR, odds ratio.

Adjusted for year of birth, gender, body mass index and smoking status.

${ }^{*} P$-value of the comparison of allelic frequencies, the major allele was used as the reference.

${ }^{* *} P$-value from the additive model.

aThe GG genotype was used as the reference.

Table 3 Quantitative traits stratified according to rs6235 genotypes in controls

\begin{tabular}{|c|c|c|c|c|c|}
\hline \multirow[b]{2}{*}{ n (\%) } & GG & CG & $\mathrm{CC}$ & \multirow[b]{2}{*}{$\beta a d j \pm$ s.e.m..$^{a}$} & \multirow[b]{2}{*}{$\mathrm{P}$ add } \\
\hline & $538(48.9)$ & $462(42.0)$ & 100(9.1) & & \\
\hline Body mass index $\left(\mathrm{kg} \mathrm{m}^{-2}\right)$ & $23.9 \pm 3.2$ & $24.4 \pm 3.3$ & $24.7 \pm 3.4$ & $0.333 \pm 0.130$ & 0.010 \\
\hline Waist circumference $(\mathrm{cm})$ & $82.2 \pm 10.7$ & $83.8 \pm 10.1$ & $84.9 \pm 10.7$ & $0.466 \pm 0.245$ & 0.058 \\
\hline Fasting glucose $\left(\mathrm{mmoll}^{-1}\right)$ & $4.8 \pm 0.4$ & $4.9 \pm 0.4$ & $5.0 \pm 0.4$ & $-0.006 \pm 0.017$ & 0.737 \\
\hline Systolic blood pressure $(\mathrm{mm} \mathrm{Hg})$ & $117.8 \pm 13.3$ & $119.6 \pm 13.4$ & $122.4 \pm 13.1$ & $1.591 \pm 0.619$ & 0.010 \\
\hline Diastolic blood pressure (mm Hg) & $77.5 \pm 8.5$ & $78.1 \pm 7.6$ & $79.8 \pm 7.2$ & $1.017 \pm 0.393$ & 0.010 \\
\hline
\end{tabular}

Abbreviation: $\beta$ adj, adjusted regression coefficient.

Continuous data are expressed as means \pm s.d.

Adjusted for year of birth, gender and body mass index.

aFrom the additive model.

spironolactone), the risk $\mathrm{C}$-allele was associated with increased PRA $(P=0.00004)$ and ANG II $(P=0.0003)$ and ALD levels $(P=0.018)$ in the EH patients (Table 5). After correction of multiple comparisons using 10000 permutations, these associations of rs6235 with PRA, ANG II and ALD remained significant (with empirical $P$-values of $0.0002,0.0004$ and 0.021 , respectively) in the $\mathrm{EH}$ patients. In the RAAS-related antagonist-stratified analysis, the rs6235 C-allele was significantly associated with increased PRA $(P=0.002)$, ANG II $(P=0.026)$ and ALD $(P=0.005)$ levels in the EH patients who were not taking RAAS-related antagonists and was associated with increased PRA $(P=0.036)$ and ANG II levels $(P=0.028)$ in the EH patients who were taking RAAS-related antagonists (Table 4). After correction of multiple comparisons using 10000 permutations, the associations of rs6235 with PRA, and ALD levels remained significant (with empirical $P$-values of $0.002,0.003$ and 0.003 , respectively) in the $\mathrm{EH}$ patients who were not taking RAAS-related antagonists; however, the other associations were no longer significant following this correction (Table 4). The associations of rs6235 with serum sodium and potassium levels were not significant in $\mathrm{EH}$ patients $(P>0.05)$ (Supplementary Table 3).

\section{Associations of rs6235 with obesity and BMI}

Of the 1112 normotensive controls, 50 were obese (as defined by a BMI $\geqslant 28 \mathrm{~kg} \mathrm{~m}^{-2}$ ). These obese subjects had a higher waist 
Table 4 Quantitative traits stratified according to rs6235 genotypes in essential hypertension patients

\begin{tabular}{|c|c|c|c|c|c|}
\hline & GG & CG & CC & & \\
\hline n (\%) & 409 (40.0) & 490 (47.9) & $124(12.1)$ & $\beta a d j \pm$ s.e.m. ${ }^{a}$ & $\mathrm{P}$ add ${ }^{\mathrm{a}}$ \\
\hline Waist circumference (cm) & $86.8 \pm 11.1$ & $87.8 \pm 10.1$ & $88.3 \pm 11.4$ & $0.273 \pm 0.374$ & 0.432 \\
\hline \multicolumn{6}{|l|}{ Plasma renin activity $\left(n g \mathrm{ml}^{-1} h^{-1}\right)^{\mathrm{b}}$} \\
\hline With RAAS-related antagnonist & $0.6(0.4-1.4)$ & $0.8(0.5-1.3)$ & $0.9(0.4-3.7)$ & $0.074 \pm 0.035$ & 0.036 \\
\hline \multicolumn{6}{|l|}{ 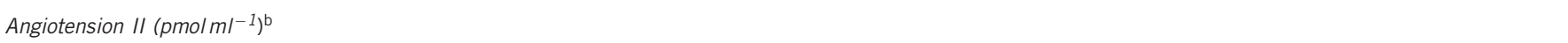 } \\
\hline All & $45.9(20.1-97.6)$ & $48.8(14.4-123.5)$ & $114.8(63.2-155.0)$ & $0.958 \pm 0.271$ & 0.0003 \\
\hline Without RAAS-related antagnonist & $54.5(14.4-103.4)$ & $83.3(31.6-201.0)$ & $71.8(54.5-137.8)$ & $1.266 \pm 0.586$ & 0.026 \\
\hline With RAAS-related antagnonist & $40.2(23.0-94.7)$ & $31.6(11.5-77.5)$ & $132.1(83.3-172.3)$ & $0.773 \pm 0.358$ & 0.028 \\
\hline With RAAS-related antagnonist & $2.2(1.9-2.5)$ & $2.2(1.9-2.8)$ & $2.5(1.8-2.5)$ & $1.9 \mathrm{E}-4 \pm 2.2 \mathrm{E}-04$ & 0.419 \\
\hline
\end{tabular}

Abbreviation: $\beta$ adj, adjusted regression coefficient; RAAS, renin angiotesin aldosterone system.

Data are expressed as means \pm s.d. or median (inter quartile range).

Adjusted for year of birth, gender, body mass index and antihypertension medications in all hypertension patients (adjusted for year of birth, gender and antihypertension medications for the analysis of bodymass index).

Adjusted for year of birth, gender and body mass index in the RAAS-related antagnonist-stratified analyses.

a From the additive model.

bVariables were log transformed before statistical analysis; numbers in the table were back transformed as median (inter quartile range).

Table 5 The associations of rs6235 and obesity

\begin{tabular}{|c|c|c|c|c|c|c|c|c|c|c|c|}
\hline \multicolumn{3}{|c|}{ Allele frequency } & \multirow[b]{2}{*}{ OR $(95 \% \mathrm{Cl})^{*}$} & \multirow[b]{2}{*}{$\mathrm{P}^{*}$} & \multicolumn{3}{|c|}{ Genotype distribution } & \multirow[b]{2}{*}{ OR $(95 \% C l)^{a}$} & \multirow[b]{2}{*}{$\mathrm{Pa}^{\mathrm{a}}$} & \multirow[b]{2}{*}{ OR $(95 \% C l)^{* *}$} & \multirow[b]{2}{*}{$\mathrm{P}$ add** } \\
\hline & Non-obesity (\%) & Obesity (\%) & & & Genotype & Non-obesity (\%) & Obesity (\%) & & & & \\
\hline G & 70.3 & 61.2 & & & GG & $519(49.4)$ & $19(38.8)$ & 1.00 (ref.) & & & \\
\hline \multirow[t]{2}{*}{ C } & 29.7 & 38.8 & $1.50(0.99-2.28)$ & 0.057 & CG & $440(41.7)$ & $22(44.9)$ & $1.37(0.73-2.57)$ & 0.324 & $1.51(1.00-2.30)$ & 0.050 \\
\hline & & & & & $\mathrm{CC}$ & $92(8.9)$ & $8(16.3)$ & $2.42(1.03-5.72)$ & 0.041 & & \\
\hline
\end{tabular}

Abbreviations: $\mathrm{Cl}$, confidence interval; OR, odds ratio.

Adjusted for year of birth and gender.

*P-value of the comparison of allelic frequencies, the major allele was used as the reference.

$* * P$-value from the additive model.

aThe GG genotype was used as the reference.

circumference and SBP and DBP levels than the non-obese controls. The distribution of gender and the percentages of smoking status were similar between the two groups in normotensive controls (Table 1). The PCSK1 rs6235 SNP was significantly associated with obesity in an additive genetic model (CC vs CG vs GG, $\mathrm{OR}=1.51$, 95\% CI (1.00-2.30), $P=0.050)$ after adjusting for gender and age. The odds ratio of CC vs GG was 2.42 (95\% CI (1.03-5.72), $P=0.041)$ (Table 5), after adjusting for gender, age and fasting glucose levels, this result was still significant (CC vs GG OR $=2.42,95 \%$ CI (1.02-5.73), $P=0.044$ ) (Supplementary Table 4). The risk C-allele was also nominally associated with increased BMI $(P=0.010)$ after adjusting for age and gender in the normotensive controls. No significant associations were found between the $\mathrm{C}$-allele and waist circumference $(P=0.058)$ or fasting glucose levels $(P=0.737)$ in the controls (Table 3). After correction of multiple comparisons using 10000 permutations, the association of rs6235 with BMI remained significant (with an empirical $P$-value of 0.008 ) in the controls. The associations of the C-allele with BMI and waist circumstance were not significant in $\mathrm{EH}$ patients $(P=0.127$ and 0.432 , respectively) (Table 4).

\section{DISCUSSION}

To the best of our knowledge, this is the first study to investigate a possible association between the rs6235 SNP in the PCSK1 gene and a predisposition to hypertension. In this study, we found that the rs6235 SNP was significantly associated with $\mathrm{BP}$, hypertension and the levels of renin, ANG II and ALD. Consistent with previous studies, ${ }^{11}$ our study also confirms the effects of rs6235 on BMI and obesity.

Our results provide evidence of an association between the common variants of PCSK1 and hypertension in the Han Chinese population. Both genetic and environmental factors are important for the pathogenesis of EH. The combination of small quantitative effects from the variants of many genes with several environmental factors increases the risk of EH. In the southern and northern areas of China, the life styles were totally different, especially for the dietary patterns; these factors significantly affected the prevalence of hypertension in 
southern and northern China. ${ }^{24}$ In this study, we enrolled the hypertension patients and control subjects from Shanghai, the biggest city of China, where our hospital is located, to avoid the bias and confounding from environmental factors.

In 2007, Farooqi et al. ${ }^{6}$ reported that the increase in plasma active renin levels upon ambulation after being recumbent overnight was lower in patients with PCSK1 deficiency than in controls, which suggests that the processing of prorenin to renin is associated with PCSK1 function in humans. Prorenin is the prohormone of renin and is primarily synthesized in the renal juxtaglomerular cells. ${ }^{25}$ In the secretory granules of juxtaglomerular cells, PCSK1 cleaves the prosegment of prorenin to yield renin. ${ }^{26}$ Thus, PCSK1 is closely coupled to renin maturation. Renin is the key hormone of RAAS and controls the first and rate-limiting steps in this pathway, namely, the conversion of angiotensinogen to angiotensin I, and regulates vascular constriction and $\mathrm{BP}^{27}$ Renin also activates the (pro)renin receptor, which triggers several mitogen-activated protein kinase signaling pathways. ${ }^{16-18}$ Altogether, through both angiotensin-dependent and -independent roles, renin has an important role in the regulation of $\mathrm{BP}$ and in the development of hypertension, atherosclerosis, cardiac remodeling and heart failure. ${ }^{28}$ These previous reports suggest that polymorphisms in the PCSK1 gene may be involved in the development of hypertension in humans.

Based on the aforementioned evidence, we further confirmed the association between the rs6235 SNP and RAAS levels in hypertensive patients, especially in the patients not taking RAAS antagonists. These results suggested that rs6235 may affect the function of PCSK1 in renin maturation in hypertensive patients. rs6235 was also associated with ANG II and ALD levels in the present study, higher renin, ANG II and ALD levels in C-allele carriers may contribute to the susceptibility of hypertension. But, we did not find any association of rs6235 with serum sodium and potassium levels in hypertension patients. The C-terminal tail of PCSK1 is associated with the protein's activity, especially in processing prorenin. ${ }^{15}$ The nonsynonymous SNP rs6235 encodes an S690T substitution in the C-terminal region of the protein that has been shown to be important for the correct targeting and specificity of PCSK1 and its sorting into secretary granules. ${ }^{29}$ However, to date, the precise function of the rs6235 SNP has remained poorly understood. In the limited functional in vitro studies that have been performed to date, the rs6235 SNP did not significantly affect enzymatic activity, ${ }^{11}$ but the rs6235 SNP was found to affect glucose-stimulated proinsulin conversion in nondiabetic subjects. ${ }^{12}$ Therefore, it is also possible that rs6235 is associated with prorenin conversion, renin maturation and renin levels. Increased renin levels would thereby promote RAAS and influence sodium balance, intravascular volume and $\mathrm{BP}$, all of which may be responsible for the association of the rs6235 SNP in the PCSK1 gene with the susceptibility to develop hypertension.

In recent years, variants of PCSK1, including rs6232 and rs6235, have been found to be associated with obesity in various ethnics. ${ }^{11,14,30}$ Consistent with this previous study, we found a significant association between the PCSK1 rs6235 SNP and BMI and obesity in our control group, which comprised 1053 normotensive and euglycemic subjects.

Both obesity and hypertension increase cardiovascular disease risk and often coexist in an individual patient. ${ }^{19}$ Our study found a possible association between a SNP in the PCSK1 gene that predisposes individuals to develop obesity and hypertension. Moreover, both of the associations of the PCSK1 rs6235 SNP with BP and hypertension were independent of BMI. Our study found that RAAS, but not obesity, may be the important intermediate of the PCSK1 rs6235 SNP for developing hypertension. The association of PCSK1 gene with hypertension and obesity emphasize the need to investigate PCSK1 and its related substrates for identification of specific therapeutic targets for treatment of both hypertension and obesity.

There were some limitations to our study. First, we did not measure the prorenin levels or the renin/prorenin ratio, which would have made the results more accurate with regard to the association of the PCSK1 rs6235 SNP with prorenin conversion. Second, the RAAS values were not measured in the normotensive controls, and the association of the PCSK1 rs6235 SNP with RAAS needs to be replicated in other populations. Third, the present study was a casecontrolled, hospital-based study. A population-based prospective study in the Chinese population (the Changfeng study) was performed, ${ }^{31}$ and the findings in the present study will be confirmed in this population. Lastly, only one SNP was tested in the present study; thus, other functional SNPs and tagging SNPs need to be studied.

In the present study, we found that the rs6235 SNP in the PCSK1 gene was associated with both $\mathrm{BP}$ and $\mathrm{EH}$, and this may have been mediated by RAAS levels. The associations of rs6235 with BMI and obesity were also confirmed in this study. Further studies are warranted to examine whether common variants in the PCSK1 gene contribute to an increased risk of hypertension and obesity in other populations.

\section{CONFLICT OF INTEREST}

The authors declare no conflict of interest.

\section{ACKNOWLEDGEMENTS}

We are grateful to all of the subjects who participated in this study. This work was supported by the Ministry of Science and Technology of China (Grant No. 2008BAI52B03), The Major Project of Subject Construction of Shanghai Bureau of Health (Grant No.08GWZX0203), The Major Program of Shanghai Municipality for Basic Research (Grant No.08dj1400601)and National Program '985' phase III (Grant No. YFX0302)

Author contributions: XL participated in the design of the study, performed the SNP genotyping and the analysis of the genotype data, and contributed to the statistical analysis and drafting of the manuscript. XG conceived the study, contributed to the design and coordination of the study, performed some statistical analyses, interpreted the findings and drafted the manuscript. DL and ZL participated in the design of the study. XL, YL (Yan Ling), YL (Ying Liu)and HC participated in sample collection and SNP genotyping. All of the authors have read and approved the final manuscript.

1 Docherty K, Steiner DF. Post-translational proteolysis in polypeptide hormone biosynthesis. Annu Rev Physiol 1982; 44: 625-638.

2 Chretien M, Benjannet S, Lazure C, Seidah NG. Biosynthesis of hormonal and neural peptides. Trans Am Clin Climatol Assoc 1984; 95: 19-25.

3 Seidah NG, Benjannet S, Hamelin J, Mamarbachi AM, Basak A, Marcinkiewicz J, Mbikay M, Chretien M, Marcinkiewicz M. The subtilisin/kexin family of precursor convertases. Emphasis on PC1, PC2/7B2, POMC and the novel enzyme SKI-1. Ann NY Acad Sci 1999; 885: 57-74.

4 Jackson RS, Creemers JW, Ohagi S, Raffin-Sanson ML, Sanders L, Montague CT, Hutton JC, O'Rahilly S. Obesity and impaired prohormone processing associated with mutations in the human prohormone convertase 1 gene. Nat Genet 1997; 16 303-306.

5 Jackson RS, Creemers JW, Farooqi IS, Raffin-Sanson ML, Varro A, Dockray GJ, Holst JJ, Brubaker PL, Corvol P, Polonsky KS, Ostrega D, Becker KL, Bertagna X, Hutton JC White A, Dattani MT, Hussain K, Middleton SJ, Nicole TM, Milla PJ, Lindley KJ, O'Rahilly S. Small-intestinal dysfunction accompanies the complex endocrinopathy of human proprotein convertase 1 deficiency. J Clin Invest 2003; 112: 1550-1560.

6 Farooqi IS, Volders K, Stanhope R, Heuschkel R, White A, Lank E, Keogh J, O'Rahilly $S$, Creemers JW. Hyperphagia and early-onset obesity due to a novel homozygous missense mutation in prohormone convertase 1/3. J Clin Endocrinol Metab 2007; 92 3369-3373. 
7 Hager J, Clement K, Francke S, Dina C, Raison J, Lahlou N, Rich N, Pelloux V, Basdevant A, Guy-Grand B, North M, Froguel P. A polymorphism in the $5^{\prime}$ untranslated region of the human ob gene is associated with low leptin levels. Int $J$ Obes Relat Metab Disord 1998; 22: 200-205

8 Chagnon YC, Rice T, Perusse L, Borecki IB, Ho-Kim MA, Lacaille M, Pare C, Bouchard L, Gagnon J, Leon AS, Skinner JS, Wilmore JH, Rao DC, Bouchard C. Genomic scan for genes affecting body composition before and after training in Caucasians from HERITAGE. J Appl Physiol 2001; 90: 1777-1787.

9 Bell CG, Benzinou M, Siddiq A, Lecoeur C, Dina C, Lemainque A, Clement $K$, Basdevant A, Guy-Grand B, Mein CA, Meyre D, Froguel P. Genome-wide linkage analysis for severe obesity in french caucasians finds significant susceptibility locus on chromosome 19q. Diabetes 2004; 53: 1857-1865.

10 Chen G. Adeyemo AA, Johnson T, Zhou J, Amoah A, Owusu S, Acheampong J, Agyenim-Boateng K, Eghan BA, Oli J, Okafor G, Abbiyesuku F, Dunston GM, Chen Y, Collins F, Rotimi C. A genome-wide scan for quantitative trait loci linked to obesity phenotypes among West Africans. Int J Obes 2005; 29: 255-259.

11 Benzinou M, Creemers JW, Choquet $H$, Lobbens S, Dina C, Durand E, Guerardel A, Boutin P, Jouret B, Heude B, Balkau B, Tichet J, Marre M, Potoczna N, Horber F, Le Stunff C, Czernichow S, Sandbaek A, Lauritzen T, Borch-Johnsen K, Andersen G, Kiess W, Korner A, Kovacs P, Jacobson P, Carlsson LM, Walley AJ, Jorgensen T, Hansen T, Pedersen O, Meyre D, Froguel P. Common nonsynonymous variants in PCSK1 confer risk of obesity. Nat Genet 2008; 40: 943-945.

12 Heni M, Haupt A, Schafer SA, Ketterer C, Thamer C, Machicao F, Stefan N, Staiger H, Haring HU, Fritsche A. Association of obesity risk SNPs in PCSK1 with insulin sensitivity and proinsulin conversion. BMC Med Genet 2010; 11: 86.

13 Corpeleijn E, Petersen L, Holst C, Saris WH, Astrup A, Langin D, MacDonald I, Martinez JA, Oppert JM, Polak J, Pedersen O, Froguel P, Arner P, Sorensen TI, Blaak EE. Obesity-related polymorphisms and their associations with the ability to regulate fat oxidation in obese Europeans: the NUGENOB study. Obesity 2009; 18: 1369-1377.

14 Qi Q, Li H, Loos RJ, Liu C, Hu FB, Wu H, Yu Z, Lin X. Association of PCSK1 rs6234 with obesity and related traits in a Chinese Han population. PLoS One 2010; 5: e10590.

15 Jutras I, Seidah NG, Reudelhuber TL, Brechler V. Two activation states of the prohormone convertase PC1 in the secretory pathway. J Biol Chem 1997; 272: 15184-15188.

16 Nguyen G, Delarue F, Burckle C, Bouzhir L, Giller T, Sraer JD. Pivotal role of the renin/ prorenin receptor in angiotensin II production and cellular responses to renin. J Clin Invest 2002; 109: 1417-1427.

17 Huang Y, Wongamorntham S, Kasting J, McQuillan D, Owens RT, Yu L, Noble NA, Border W. Renin increases mesangial cell transforming growth factor-betal and matrix proteins through receptor-mediated, angiotensin II-independent mechanisms. Kidney Int 2006; 69: 105-113.

18 Schefe JH, Menk M, Reinemund J, Effertz K, Hobbs RM, Pandolfi PP, Ruiz P, Unger T, Funke-Kaiser H. A novel signal transduction cascade involving direct physical interaction of the renin/prorenin receptor with the transcription factor promyelocytic zinc finger protein. Circ Res 2006; 99: 1355-1366.

19 Isomaa B, Almgren P, Tuomi T, Forsen B, Lahti K, Nissen M, Taskinen MR, Groop L. Cardiovascular morbidity and mortality associated with the metabolic syndrome. Diabetes Care 2001; 24: 683-689.

20 Chalmers J, MacMahon S, Mancia G, Whitworth J, Beilin L, Hansson L, Neal B, Rodgers A, Ni Mhurchu C, Clark T. 1999 World Health Organization-International Society of Hypertension Guidelines for the management of hypertension. Guidelines sub-committee of the World Health Organization. Clin Exp Hypertens 1999; 21: 1009-1060.

21 Chen C, Lu FC. The guidelines for prevention and control of overweight and obesity in Chinese adults. Biomed Environ Sci 2004; 17(Suppl): 1-36.

22 Campbell DJ, Nussberger J, Stowasser M, Danser AH, Morganti A, Frandsen E, Menard J. Activity assays and immunoassays for plasma Renin and prorenin: information provided and precautions necessary for accurate measurement. Clin Chem 2009; 55: $867-877$.

23 Purcell S, Neale B, Todd-Brown K, Thomas L, Ferreira MA, Bender D, Maller J, Sklar P, de Bakker PI, Daly MJ, Sham PC. PLINK: a tool set for whole-genome association and population-based linkage analyses. Am J Hum Genet 2007; 81: 559-575.

24 Wang D, He Y, Li Y, Luan D, Yang X, Zhai F, Ma G. Dietary patterns and hypertension among Chinese adults: a nationally representative cross-sectional study. BMC Public Health 2011; 11: 925.

25 Kurtz A. Renin release: sites, mechanisms, and control. Annu Rev Physiol. 2011; 73 : 377-399.

26 Danser AH, Batenburg WW, van Esch JH, Krop M. Prorenin anno 2008. J Mol Med 2008; 86: 655-658.

27 Simoes ESAC, Flynn JT. The renin-angiotensin-aldosterone system in 2011: role in hypertension and chronic kidney disease. Pediatr Nephrol (e-pub ahead of print 23 September 2011).

28 Abassi Z, Winaver J, Feuerstein GZ. The biochemical pharmacology of renin inhibitors: implications for translational medicine in hypertension, diabetic nephropathy and heart failure: expectations and reality. Biochem Pharmacol 2009; 78: 933-940.

29 Zhou Y, Lindberg I. Enzymatic properties of carboxyl-terminally truncated prohormone convertase 1 (PC1/SPC3) and evidence for autocatalytic conversion. J Biol Chem 1994; 269: 18408-18413.

30 Chang YC, Chiu YF, Shih KC, Lin MW, Sheu WH, Donlon T, Curb JD, Jou YS, Chang TJ, Li HY, Chuang LM. Common PCSK1 haplotypes are associated with obesity in the Chinese population. Obesity 2010; 18: 1404-1409.

31 Gao X, Hofman A, Hu Y, Lin H, Zhu C, Jeekel J, Jin X, Wang J, Gao J, Yin Y, Zhao N. The Shanghai Changfeng Study: a community-based prospective cohort study of chronic diseases among middle-aged and elderly: objectives and design. Eur J Epidemiol 2010; 25: 885-893.

Supplementary Information accompanies the paper on Hypertension Research website (http://www.nature.com/hr) 